\title{
VARIABLE FMRI ACTIVATION DURING TWO DIFFERENT LANGUAGE TASKS IN A PATIENT WITH COGNITIVE DELAY
}

\author{
Sara Escorsi-Rosset', Lauro Wichert-Ana², Marino Muxfeldt Bianchin ${ }^{3}$, \\ Tonicarlo Rodrigues Velasco ${ }^{4}$, Américo C. Sakamoto5 ${ }^{5}$ João Pereira Leite ${ }^{6}$, \\ Antonio Carlos Santos 7 , Dráulio Barros de Araújo ${ }^{8}$
}

\begin{abstract}
Functional MRI produces a more accurate localization of the language areas for epilepsy surgery purpose, but requires the patient cooperation. We report a 34 years-old woman with mental retardation who underwent two different verbal fluency tasks, category and word naming. We found a strong activation of the Broca's area in the most difficult task. We suggest that a multi-task fMRI study could be successful in patients with cognitive delay.
\end{abstract}

KEY WORDS: fMRI, language, epilepsy surgery, cognitive delay.

\begin{abstract}
Ativação variável da ressonância magnética funcional com duas tarefas diferentes em um paciente com retardo mental

RESUMO - A ressonância magnética funcional permite uma localização acurada da área da linguagem para fins de cirurgia de epilepsia, mas requer a colaboração do paciente na execução da tarefa proposta, o que pode limitar a sua utilização em pacientes com retardo mental. Nós apresentamos o caso de uma mulher com 34 anos de idade, com retardo mental, que foi submetida a duas tarefas distintas de geração silenciosa de palavras, por categoria e letras. Encontramos forte ativação da área de Broca na tarefa mais complexa. Sugerimos que um estudo com múltiplas tarefas pode ser útil em pacientes com retardo mental.
\end{abstract}

PALAVRAS-CHAVE: ressonância magnética funcional, fMRI, linguagem, cirurgia de epilepsia, retardo mental.

Epilepsy surgery is usually an elective procedure in which the complete resection of the epileptogenic zone is of paramount importance. Moreover, potentially eloquent cortex should be preserved, avoiding new, unacceptable deficits to the patient ${ }^{1}$. In such procedures, the prediction of whether a given cortical area would be deemed essential for language processing is of great importance for presurgical workup. For that purpose, the Wada test remains as the gold standard ${ }^{2,3}$. However, it requires an invasive angiographic procedure and has technical difficulties related to the significant variability of vascular anatomy ${ }^{4}$. Also, it anesthetizes a large brain area only classifying patients in left, bilateral or right language domi- nants, and does not produce an accurate assessment of language areas.

There is a growing trend toward the use of functional MRI (fMRI) instead of the Wada test. fMRI has the advantages to be non-invasive, carrying less morbidity and assessing a more accurate mapping of the language areas. Unfortunately, BOLD-fMRI studies of language require cooperation from epileptic patients, which frequently have behavioral, cognitive and motor disabilities.

We aim to report both the feasibility of the fMRI study and the variability in the fMRI activation with two different, clinically used, language paradigms in an epileptic patient with mental retardation.

\footnotetext{
'Psychologist, Doctorate Student, Epilepsy Surgery Center (CIREP), Department of Neurology, Psychiatry and Clinical Psychology, Ribeirão Preto School of Medicine, University of São Paulo, Ribeirão Preto SP, Brazil (FMRP/USP); ${ }^{2}$ MD, PhD, Epilepsy Surgery Center (CIREP), Department of Neurology, Psychiatry and Clinical Psychology, FMRP/USP; ${ }^{3 M D}$, PhD, Professor, Division of Neurology, Department of Internal Medicine, Federal University of Rio Grande do Sul, Porto Alegre RS, Brazil (UFRGS); ${ }^{4}$ MD, PhD, Epilepsy Surgery

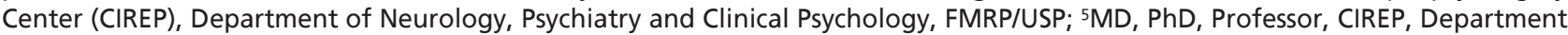
of Neurology, Psychiatry and Clinical Psychology, FMRP/USP; ${ }^{6}$ MD, PhD, Professor, Department of Neurology, Psychiatry and Clinical Psychology, FMRP/USP; ${ }^{7}$ MD, PhD, Professor, Imaging Science and Medical Physics Center of the Department of Internal Medicine, FMRP/USP; ${ }^{8}$ Physicist, PhD, Professor, Department of Physics and Math, FFCLRP, University of São Paulo, Ribeirão Preto SP, Brazil.
}

Received 20 March 2007, received in final form 29 June 2007. Accepted 22 August 2007.

Dr. Draulio Barros de Araújo - Centro de Imagens / Hospital das Clínicas / FMRP - Avenida Bandeirantes 3900 - 14048-900 Ribeirão Preto SP - Brazil. E-mail: draulio@usp.br 


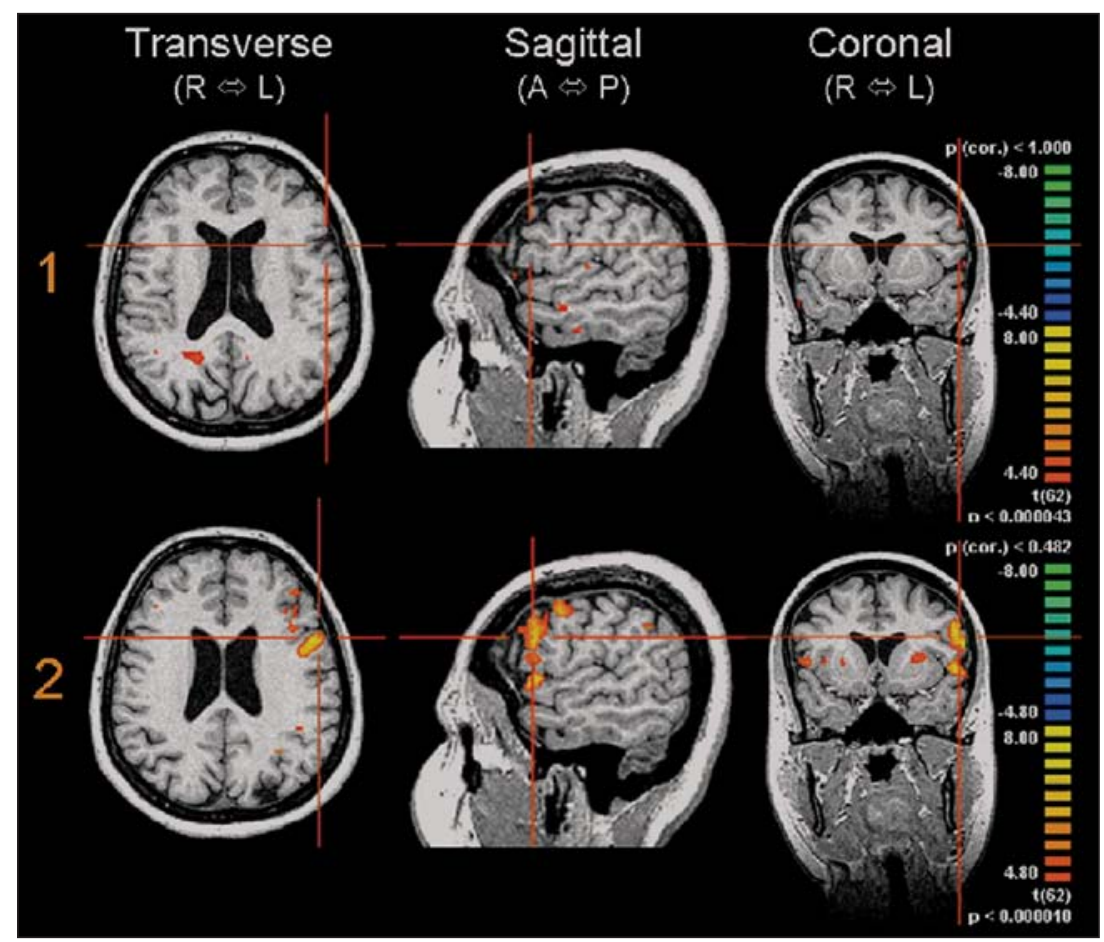

Figure. Functional MRI with two different verbal fluency tasks in an epileptic patient with cognitive delay. (1) Paradigm One performed with verbal fluency task by category showing no activation in the Broca's area. (2) Paradigm Two performed with verbal fluency task by word naming showing strong activation in the Broca's area. $R$, right; $L$, left; $A$, anterior and $P$, posterior.

\section{CASE}

A right-handed 34 years-old woman started with sporadic epileptic seizures at two years of age. One of these events was prolonged characterizing status epilepticus. At 21 years, she developed highly frequent seizures and initiated the use of antiepileptic drugs (AEDs). She became pharmaco-resistant to AEDs and was referred to our epilepsy surgery center for a presurgical workup.

The 1.5T MRI showed right predominant bilateral mesial temporal sclerosis and the computed tomography (CT) showed a calcified neurocysticercotic lesion in the posterior region of right temporal lobe. Surface video-electroencephalographic monitoring (VEEG) showed normal background activity with $81 \%$ of interictal spikes in the right sphenoidal electrode and $19 \%$ in the left one. The patient had eight complex partial seizures shared in two semiological and EEG patterns suggesting independent seizure onset in bilateral temporal lobes. Neuropsychological test evidenced mental retardation and diffuse cognitive impairment, with estimated IQ of 64 . Wada test showed left hemispheric dominance for speech and bilateral cognitive reserve for memory, which could allow surgical procedure in any of the temporal lobes.

fMRI comprised of two language tasks of word generation. The patient underwent "dry run" training before the scanning to ensure task compliance. The patient performed two paradigms: category and word naming. In the first task, the patients were asked to brain-generate (in complete silence) as many elements as possible from a specific category (animals, fruits, colours, objects and places) until cued to stop ${ }^{5}$. In the second task ${ }^{6}$, patients were asked to think silently of as many words as possible starting with a specified letter (M, A, E , C and S). In both paradigms six blocks
27 seconds of rest were interleaved with five blocks of activity. $\mathrm{fMRI}$ data set was obtained in EPI-BOLD sequences, and was co-registered with high spatial resolution images (3D gradient-echo T1 weighted sequence), covering the entire the brain. Individual fMRI data were analyzed with a General Linear Model $(p<0.00001)$, using the Brain Voyager QXTM. The analysis revealed no $\mathrm{FMRI}$ brain activation in the main language areas during category naming (Figure row 1), while word naming activated left inferior frontal gyrus and superior temporal gyrus (Figure row 2). Subcortically, the left thalamus was also activated.

Finally, the patient underwent invasive EEG with deep electrodes confirming the bilaterality of seizure onset, thus precluding epilepsy surgery.

\section{DISCUSSION}

In this case report we showed very distinct results from two different language paradigms, generally used in the clinical setting for fMRI. Additionally, we showed that mental retardation did not preclude the fMRI feasibility in the present patient.

Several fMRI studies have applied different methods for the lateralization of linguistic functions. The choice of a suitable method should follow at least three criteria: robustness (results do not vary with parameters), the capability of inter-subject comparison, and reproducibility?. We used two paradigms of verbal fluency among several that have commonly been employed worldwide, and the choice of a specific one depends on the preference of each investigator. 
While category naming did not activate language centers of our patient, the word naming resulted in a strong activation. This fact was remarkable once this last paradigm has a higher degree of difficult considering the cognitive deficit of the patient.

We believe that applying more than one paradigm for language may compensate eventual deficiencies of a single task, being an alternative to avoid the weakness observed in isolated paradigms. This has a particular role when considering each individual as exposed to different extrinsic and intrinsic factors during his/her lifetime, configuring each one as a unique neural network. Therefore, different individuals certainly use different strategies to accomplish specific tasks. In this setting, fMRI seems to be a powerful instrument to study these particularities, and is far superior to the Wada test.
Acknowledgments - This study was supported by "The State of São Paulo Research Foundation", FAPESP (Grant 04/14004-CInAPCe Program).

\section{REFERENCES}

1. Rosenow F, Luders H. Presurgical evaluation of epilepsy. Brain 2001; 124:1683-1700.

2. Branch C, Milner B, Rasmussen T. Intracarotid sodium amytal for the lateralization of cerebral speech dominance: observations in 123 patients. J Neurosurg 1964;21:399-405.

3. Wada J, Rasmussen T. Intracarotid injection of sodium amytal for the lateralization of cerebral speech dominance: experimental and clinical observations. J Neurosurg 1960;17:266-282.

4. Baxendale S, Thompson P, Duncan J, Richardson M. Is it time to replace the Wada test? Neurology 2003;60:354-355

5. Gaillard WD, Sachs BC, Whitnah JR, et al. Developmental aspects of language processing: fMRI of verbal fluency in children and adults. Hum Brain Mapp 2003;18:176-185.

6. Pujol J, Deus J, Losilla JM, Capdevila A. Cerebral lateralization of language in normal left-handed people studied by functional MRI. Neurology 1999;52:1038-1043.

7. Nagata SI, Uchimura K, Hirakawa W, Kuratsu JI. Method for quantitatively evaluating the lateralization of linguistic function using functional MR imaging. Am J Neuroradiol 2001;22:985-991. 